\title{
Strategi Peningkatan Daya Saing Produk Suku Cadang Otomotif dan Elektonik Berbahan Karet di PT BesQ Sarana Abadi
}

\author{
Strategies to Increase the Competitiveness of Rubber and Automotive Parts Products \\ at PT BesQ Sarana Abadi
}

\author{
Imron Hanafi ${ }^{1 *}$, Aida Vitalaya S Hubeis ${ }^{2 \sharp}$, dan Sapta Raharja ${ }^{3 \sharp}$ \\ ${ }^{1}$ Program Magister Pengembangan Industri Kecil Menengah, Sekolah Pascasarjana IPB \\ 2 Departemen Komunikasi dan Pengembangan Masyarakat, FEMA IPB \\ ${ }^{3}$ Departemen Teknologi Industri Pertanian, Fateta IPB \\ * Jl. Kamper Kampus IPB Darmaga Bogor 16680
}

\begin{abstract}
ABSTRAK
Dalam rangka memacu industri otomotif dan elektronik untuk memenuhi kebutuhan dalam negeri dan bersaing di era globalisasi, maka pengembangan industri manufaktur tidak hanya bertumpu pada industri berskala besar, tetapi perlu dikembangkan ke Usaha Kecil Menengah (UKM). Kendala yang dihadapi saat ini adalah keterbatasan modal, sumber daya manusia (SDM), pengembangan produk dan kasus pemasaran. PT BesQ Sarana Abadi merupakan UKM yang bergerak dibidang usaha pembuatan suku cadang berbahan karet. Dalam rangka meningkatkan daya saing maka PT BesQ Sarana Abadi diteliti dengan perumus strategi daya saing yang tepat. Tujuan penelitian: (1) mengidentifikasi faktor-faktor yang memengaruhi keunggulan daya saing produk suku cadang otomotif dan elektonik berbahan karet; (2) menganalisis faktor internal dan eksternal yang memengaruhi daya saing industri produk suku cadang otomotif dan elektronik berbahan karet dengan metode Internal Factor Evaluation (IFE) dan External Factor Evaluation (EFE); (3) menyusun strategi daya saing industri produk suku cadang otomotif dan elektonik berbahan karet dengan metode Internal-External (IE) dan Strengths, Weakness, Opportunities, Threats (SWOT), serta Balance Score Card (BSC); (4) menyusun prioritas strategi untuk meningkatkan daya saing industri produk suku cadang otomotif dan elektonik berbahan karet dengan metode Quantitative Strategic Planning Matrix (QSPM). Dari hasil analisis didapatkan banyak kelemahan dalam perusahaan. Dalam hal ini nilai peluang yang tinggi mengakibatkan perusahaan bisa beroperasi, karena pada matriks IFE nilai kekuatan lebih besar dibandingkan dengan nilai kelemahan. Pada matriks EFE, nilai peluang lebih besar dibandingkan dengan ancaman. Dengan metode SWOT dan BSC teridentifikasinya strategi yang diperlukan, ditetapkannya skala prioritas strategi dengan menggunakan metode QSPM.
\end{abstract}

Kata kunci: daya saing, produk suku cadang berbahan karet, strategi

\begin{abstract}
In order to spur the automotive and electronic industries to meet domestic needs and compete in the era of globalization, the development of manufacturing industries is not only based on large-scale industries, but also needs to be developed into Small and Medium Enterprises (SMEs). The obstacles faced today are limited capital, human resources (HR), product development and marketing procedures. PT BesQ Sarana Abadi is a small and medium business (UKM) engaged in the business of making rubber parts. In order to improve competitiveness, PT BesQ Sarana Abadi is researched with the formulation of the right competitiveness strategy. The objectives of the study are: (1) to identify factors that influence the competitive advantage of rubber and automotive parts products; (2) analyzing internal and external factors that affect the competitiveness of rubber and automotive parts industry products using the Internal Factor Evaluation (IFE) and External Factor Evaluation (EFE) methods; (3) develop competitiveness strategies for the automotive and electronic spare parts products industry using Internal-External (IE) methods and Strengths, Weakness, Opportunities, Threats (SWOT) and Balance Score Cards (BSC); (4) formulating
\end{abstract}

\footnotetext{
*) Korespondensi:

JL. Singgalang Blok A3 no 14, Bukit Permai, 02/011, Cibubur, Ciracas, Jakarta Timur 13720; email: imron.inquest@yahoo.com
} 
priority strategies to improve the competitiveness of rubber and automotive parts industry products using the Quantitative Strategic Planning Matrix (QSPM) method. From the analysis results, there are many weaknesses in the company. In this case a high opportunity value causes the company to operate, because in the IFE matrix the value of strength is greater than the value of weakness. In the EFE matrix, the opportunity value is greater than the threat. With the SWOT and BSC methods identified strategies needed, set the priority of the strategy by using the QSPM method.

Key words: competitiveness, rubber parts products, strategy

\section{PENDAHULUAN}

Menurut Gabungan Industri Alat-alat Mobil dan Motor (GIAMM, 2015) yang merupakan wadah dari perusahaan komponen otomotif pada tahun 2011 penjualan komponen otomotif mencapai 31 juta unit, ekspor meningkat hingga 134 juta unit, dan produksi meningkat menjadi 245 juta unit. Trend perkembangan produksi dan penjualan komponen ini akan terus meningkat seiring dengan peningkatan penjualan motor di Indonesia. Industri penunjang komponen otomotif juga ikut berkembang yaitu salah satunya industri suku cadang berbahan karet. PT Astra Auto Part merupakan salah satu perusahaan yang bersaing dalam memproduksi suku cadang dari kendaraan bermotor membutuhkan komponen berbahan karet yang tidak hanya diproduksi di lingkungan groupnya. PT Velasto Indonesia salah satu perusahaan yang memproduksi suku cadang berbahan karet yang memasok PT Astra Auto Part. PT Velasto Indonesia dalam memproduksi menyerahkan sebagian produksi kepada vendor yaitu PT BesQ Sarana Abadi

Organisasi dalam menjalankan usahanya diperlukan strategi yang diperlukan untuk meningkatkan daya saing usahanya. PT BesQ Sarana Abadi adalah perusahaan bergerak dalam bidang pembuatan suku cadang yang berbahan karet (rubber) dan metal baik untuk suku cadang otomotif dan elektonik yang berdiri dari tahun 2009 dan berdomisi di Kota Bekasi. Produk yang dihasilkan adalah rubber part untuk otomotif, elektronik dan kontruksi.

Tujuan penelitian adalah:

1. Mengidentifikasi faktor-faktor yang memengaruhi keunggulan daya saing produk suku cadang otomotif dan elektonik berbahan karet

2. Menganalisis faktor internal dan eksternal yang memengaruhi daya saing industri produk suku cadang otomotif dan elektronik berbahan karet dengan matrik Internal Factor Evaluation (IFE) dan External Factor Evaluation (EFE)
3. Menyusun strategi daya saing industri produk suku cadang otomotif dan elektonik berbahan karet dengan matriks Internal-External (IE) dan Strengths, Weakness, Opportunities, Threats (SWOT) serta Balance Score Card (BSC)

4. Menyusun prioritas strategi untuk meningkatkan daya saing industri produk suku cadang otomotif dan elektonik berbahan karet dengan Quantitative Strategic Planning Matrix (QSPM).

\section{METODE PENELITIAN}

Penelitian ini dilaksanakan di PT BesQ Sarana Abadi pada bulan April sampai dengan Mei 2018. Responden internal dalam penelitian ini adalah direktur, plant manajer, Admin manajer, Marketing manajer. Responden eksternal dalam penelitian ini adalah pihak perwakilan PT Velasto, dan pemerintah daaerah sekitar. Data yang digunakan dalam penelitian ini merupakan data primer dan sekunder. Data primer merupakan data hasil observasi langsung dalam bentuk wawancara dengan bantuan kuesioner. Focus Group Discussion (FGD) yang dilakukan sebelum melakukan pengisian kuesiner. Kuesioner pada penelitian ini terdiri dari empat bagian, yaitu: (1) bagian harapan stakeholder; (2) bagian IFE dan EFE; (3) bagian SWOT BSC; dan (4) bagian QSPM. Data sekunder PT BesQ Sarana Abadi diperoleh dari data laporan perusahaan dan data lainnya yang berhungan dengan penelitian.

Data yang diperoleh diolah dan dianalisis secara destriktif kuantitatif seperti pada penelitian Katurini (2015):

1. Mengidentifikasi faktor-faktor yang memengaruhi keunggulan daya saing produk suku cadang otomotif dan elektonik berbahan karet

Manajemen strategi adalah semua hal tentang memperoleh dan mempertahankan keunggulan bersaing (Competitive advantage). Untuk itu perusahaan harus berusaha untuk memperoleh keunggulan bersaing berkelanjutan dengan: (1) beradaptasi terhadap perubahan tren eksternal, 
kejadian dan kapabilitas kompetensi internal; dan (2) secara efektif memformulasi, mengimplementasi, dan mengevaluasi strategi utama (David, 2015).

2. Melakukan evaluasi faktor internal dan eksternal

Analisis kondisi lingkungan internal dan eksternal dilakukan matriks IFE, EFE dan analisis SWOT seperti pada penelitian Katurini (2015). Jumlah faktor tidak memiliki pengaruh terhadap kisaran total skor pembobotan, karena total bobot berjumlah 1,00. Penentuan faktor bobot setiap perubah dilakukan dengan mengajukan identifykasi faktor internal dan eksternal serta strategi kepada pihak manajemen yang menentukan kebijakan perusahaan yang menggunakan metode pairwise comparasion (Kinner dan Taylor, 1991). Metode ini digunakan untuk memberikan bobot terhadap setiap faktor penentu internal dan eksternal. Setiap perubah digunakan skala 1, 2, dan 3 untuk menentukan bobot. Skala yang digunakan adalah:

$1=$ jika indikator horizontal kurang penting dibandingkan indikator vertikal

$2=$ jika indikator horizontal sama penting dibandingkan indikator vertikal

$3=$ jika indikator horizontal lebih penting dibandingkan indikator vertikal

Cara membaca perbaikan dimulai peubah pada indikator horizontal dengan peubah pada indikator vertical secara konsisten. Bobot setiap peubah diperoleh dengan menentukan nilai setiap peubah terhadap jumlah nilai keseluruhan peubah dengan menggunakan rumus (Kinner dan Taylor, 1991)

$$
a i=-\frac{X i}{\Sigma X i}
$$

Keterangan:

ai = bobot faktor

$\mathrm{Xi}=$ nilai variable $\mathrm{ke}-\mathrm{i}$

$\Sigma X i=$ total nilai peubah

Jumlah dari semua bobot terhadap faktor harus sama dengan 1,0 dan setelah melakukan pembobotan dilakukan peringkat.

Menurut David (2015), berilah peringkat 1- 4 bagi setiap faktor eksternal (EFE) kunci untuk mengidentifikasi strategi perusahaan saat ini merespons terhadap faktor itu, skalla $4=$ responsnya superior, $3=$ responnya di atas rataan, 2 = responnya rata-rata, dan 1 = responnya buruk. Peringkat didasarkan pada efektifitas strategi perusahaan. Pemberian peringkat untuk faktor internal (IFE) dengan skala 1 = kelemahan utama, 2 $=$ kelemahan minor, $3=$ kekeuatan minor dan $4=$ kekuatan utama. Pembobotan dikalikan dikalikan dengan peringkat dari setiap faktor untuk menentukan skor bobot terhadap masing-masing faktor. Penentuan skor bobot total penjumlahan secara vertikal dari semua hasil kali antara nilai dari pembobotan dengan peringkat. Total skor pembobotan dengan peringkat berkisar 1,00-4,00 dengan skor nilai IFE rataan 1,00-2,5 mencirikan organisasi yang lemah secara internal, namun bila nilai rata-ratanya berada di atas 2,5 mengidentifikasikan posisi internal kuat. Total skor pembobotan EFE 1,0 menunjukkan strategi perusahaan tidak mampu memanfaatkan peluang yang ada atau menghindari ancaman yang muncul dan jika skor bobot totalnya 4,0 mengidentifikasikan bahwa perusahaan merespon peluang dan ancaman yang ada dengan sangat baik (David, 2015).

\section{Analisis matriks IE, SWOT dan BSC}

Matriks IE berguna untuk menempatkan divisi organisasi dalam sebuah diagram sistematik dengan tampilan sembilan sel. Matriks IE didasarkan pada dua dimensi kunci, yaitu skor bobot total IFE pada sumbu $x$ dan skor bobot total EFE pada sumbu y. Pada sumbu $x$ dari matriks IE, skor bobot IFE 1,0-1,99 menunjukkan posisi internal yang lemah, skor 2,0-2,99 sedang, dan 3,04,0 adalah kuat. Pada sumbu y, skor bobot total EFE 1,0-1,99 rendah, skor 2,0-2,99 sedang dan skor 3,0-4,0 adalah tinggi.

Matrik SWOT merupakan alat untuk membantu manajer mengembangkan empat tipe strategi, yaitu SO (Strengths-opportunites), WO (Weakness-opportunities), ST (strengths-threats), dan WT (Weakness-threats). Mencocokkan faktor eksternal dan internal kunci merupakan hal yang paling sulit dalam mengembangkan matriks SWOT dan membutuhkan penilaian baik (David, 2015). Strategi SO menggunakan kekuatan internal perusahaan untuk memanfaatkan peluang eksternal. Stretegi WO bertujuan memperbaiki kelemahan internal dengan memanfaatkan peluang eksternal. Strategi ST menggunakan kekuatan internal untuk menghindari atau mengurangi ancaman dari eksternal. Strategi WT adalah taktik defensive yang diarahkan pada pengurangan kelemahan internal dan menghindari ancaman eksternal.

Matriks SWOT yang dikombinasi dengan BSC menurut Rangkuti (2017) Strategi SWOT BSC memiliki beberapa keunggulan dengan metode strategi biasa, yaitu: 
a. memiliki tiga perspektif tambahan selain perspektif finansial

b. penggunaan indikator ukuran hasil (indicatore lagging) dan indikator, indikator pemicu inerja (indicatore leading)

c. Hubungan sebab akibat

d. Penerapannya secara berjenjang di seluruh organisasi

e. Pembelajaran double loop learning

Tahapan penyusunan strategi SWOT-BSC dilakukan setelah matriks SWOT didapat dan selanjutnya menentukan ukuran dalam SWOTBSC yang bertujuan menentukan ukuran apa yang ingin dipakai dan bagaimana cara mengukurnya.

4. Merumuskan strategi prioritas perusahaan dengan QSPM

Teknis analisis QSPM digunakan untuk pembuatan peringkat strategi yang menghasilkan daftar prioritas yang didesain untuk menentukan daya tarik relatif dari tindakan yang layak. QSPM atau matriks perencanaan strategi kuatitatif adalah alat yang memungkinkan penyusun strategi mengevaluasi alternatif strategi secara obyektif sesuai faktor keberhasilan kunci internal dan eksternal yang telah diidentifikasi sebelumnya. Secara konsep QSPM menentukan daya tarik relatif dari berbagai strategi sesuai faktor keberhasilan kunci internal dan eksternal yang dapat dimafaatkan dan diperbaiki (David, 2015).

Tahapan kerja pengolahan data dengan QSPM (David, 2009) adalah:

a. Membuat daftar peluang dan ancaman eksternal, serta kekuatan dan kelemahan internal kunci perusahaan pada kolom kiri dalam QSPM. Informasi ini harus diambil

b. Pemberian bobot untuk masing-masing faktor internal dan eksternal. Bobot ini identik dengan yang ada pada matriks EFE dan IFE. Bobot disajikan dalam kolom di samping kanan faktor keberhasilan kunci internal dan eksternal

c. Evaluasi matriks tahap pencocokan dan identifikasi alternatif strategi yang harus dipertimbangkan organisasi untuk dimplementasikan. Strategi-strategi ini dicatat pada baris atas dari QPM. Strategi dikelompokkan ke dalam gugus independen, jika memungkinkan

d. Menentukan nilai daya tarik (Attractiveness Score atau AS) yang didefinisikan sebagai angka yang mengidentifikasi daya Tarik relatif dari masing-masing strategi dalam gugus alternatif tertentu. Nilai daya tarik sebagai berikut: $1=$ tidak menarik; 2 = agak menarik; 3 = cukup menarik; 4 = sangat menarik. e. Menghitung total nilai daya tarik (Total Attractiveness Score atau TAS) yang didefinisikan sebagai hasil dari pengalian bobot (langkah 2) dengan nilai daya Tarik (langkah d) dalam masing-masing baris. Semakin tinggi total nilai daya tarik, maka semakin menarik alternatif strategi tersebut.

\section{HASIL DAN PEMBAHASAN}

PT BesQ Sarana Abadi, sebuah perusahaan IKM yang bergerak pada bidang industri suku cadang berbahan baku karet. Pemilihan lokasi penelitian dilakukan secara sengaja (purposive), lokasi pabrik di kampung kelapa dua no. 7b, Desa Pedurenan, Kecamatan Mustika Jaya, Kota Bekasi, Jawa Barat. Visi PT BesQ Sarana Abadi menjadi mitra pilihan dengan kompetensi terbaik dan misinya mengembangkan industri komponen berbahan karet, dan supporting proses surface treatment dan produk dari metal.

Produk yang dijual oleh PT BesQ Sarana Abadi terdiri dari tiga jenis, yaitu komponen berbahan baku karet, support produk baut dan metal surface treatment. PT BesQ memproduksi komponen otomotif dan elektronik yang berbahan baku karet.

\section{Evaluasi faktor internal dan eksternal}

Identifikasi faktor internal perusahaan menghasilkan beberapa faktor strategik yang berupa kekuatan dan kelemahan. Identifikasi faktor eksternal perusahaan menghasilkan faktor strategi berupa kesempatan dan acnaman. Faktorfaktor tersebut diberikan pembobotan dan pemberian rating oleh masing-masing nara sumber. Hasilnya diformulasikan dalam bentuk matriks IFE. Nilai yang diperoleh dari matrik IFE menunjukkan kemampuan perusahaan dalam memanfaatkan kekuatan untuk menutupi kelemahan yang ada. (David, 2009 dan Hunger, 2012). Matriks IFE yang didapat bisa dilihat di Tabel 1. Matrik EFE yang didapat bisa dilihat di Tabel 2

Kelemahan utama PT BesQ Sarana Abadi adalah kondisi cast flow keuangan bermasalah dengan rating 0,12 dan itu juga faktor efektivitas operasional mesin rendah (ratingnya 0,1). Hasil pengidentifikasian faktor-faktor eksternal yang memengaruhi strategi perusahaan dan selanjutnya dievaluasi respon perusahaan terhadap faktorfaktor eksternal sehingga diketahui seberapa besar memengaruhi strategi faktor-faktor eksternal peluang dan ancaman tersebut. 
Tabel 1. IFE PT BesQ Sarana Abadi

\begin{tabular}{lccc}
\hline Faktor kunci & $\begin{array}{c}\text { Bobot } \\
(\mathrm{a})\end{array}$ & $\begin{array}{c}\text { Rating } \\
(\mathrm{b})\end{array}$ & $\begin{array}{c}\text { Rating Berbobot } \\
(\mathrm{axb})\end{array}$ \\
\hline Kekuatan & & & \\
\hline Tersedianya mesin untuk produksi & 0,13 & 3 & 0,39 \\
Tersedianya teknologi untuk staf & 0,08 & 3 & 0,22 \\
Tersedianya transportasi untuk pengiriman & 0,11 & 3 & 0,32 \\
Tersedianya SMM ISO 9001:2015 & 0,05 & 3 & 0,16 \\
Tersedianya teknologi informasi & 0,10 & 3 & 0,27 \\
\hline \multicolumn{1}{c}{ Sub total } & & & 1,37 \\
\hline Kelemahan & 0,12 & 1,67 & 0,20 \\
\hline Kondisi castflow keuangan bermasalah & 0,09 & 1 & 0,09 \\
Rejection Rate tinggi & 0,10 & 1 & 0,10 \\
Efektivitas operasional mesin rendah & 0,08 & 1 & 0,08 \\
Pelatihan terhadap operator kurang & 0,06 & 1 & 0,06 \\
Mesin yang digunakan mesin produksi lama & 0,09 & 1 & 0,08 \\
Sistem manajemen mutu belum dijalankan & & & 0,63 \\
\hline \multicolumn{2}{c}{ Sub total IFE } \\
\hline
\end{tabular}

Tabel 2. EFE PT BesQ Sarana Abadi

\begin{tabular}{|c|c|c|c|}
\hline Faktor kunci & $\begin{array}{l}\text { Bobot } \\
\text { (a) }\end{array}$ & $\begin{array}{l}\text { Rating } \\
\text { (b) }\end{array}$ & $\begin{array}{l}\text { Rating Berbobot } \\
(\mathrm{axb})\end{array}$ \\
\hline \multicolumn{4}{|l|}{ Peluang } \\
\hline Tingginya permintaan kendaraan bermotor & 0,09 & 4 & 0,36 \\
\hline Pemanfaatan tenaga kerja sekitar & 0,06 & 3,67 & 0,21 \\
\hline Tren permintaan kendaraan bermotor stabil & 0,04 & 4 & 0,18 \\
\hline Pelanggan merupakan perusahaan besar & 0,06 & 4 & 0,22 \\
\hline Besarnya pengguna kendaraan bermotor & 0,07 & 3,33 & 0,23 \\
\hline Meningkatnya industri manufaktur & 0,06 & 4 & 0,25 \\
\hline Sub total & & & 1,45 \\
\hline \multicolumn{4}{|l|}{ Ancaman } \\
\hline Ketergantungan material sama suppllier & 0,10 & 2 & 0,21 \\
\hline Lingkungan sekitar pabrik kurang mendukung & 0,09 & 2 & 0,18 \\
\hline Harga BBM naik & 0,11 & 1,33 & 0,14 \\
\hline Kenaikan UMR & 0,11 & 2 & 0,22 \\
\hline Kenaikan listrik & 0,11 & 2 & 0,22 \\
\hline Melemahnya rupiah & 0,11 & 1,33 & 0,14 \\
\hline Sub total & \multicolumn{3}{|r|}{1.10} \\
\hline Total IFE & \multicolumn{3}{|r|}{2.55} \\
\hline
\end{tabular}

Hasil analisis EFE menunjukkan total nilai tertimbang 2,55. Total nilai tertimbang tesebut menunjukkan posisi eksternal PT BesQ Sarana Abadi di atas rataan $(>2,50)$. Faktor peluang paling tinggi yang dihadapi oleh perusahaan adalah tingginya permintaan kendaraan bermotor dengan nilai tertimbang 0,09 . Selain itu faktor peluang tertinggi selanjutnya adalah faktor besarnya pengguna kendaraan bermotor nilai tertimbang 0,7.

\section{Formulasi strategi perusahaan}

Langkah awal formulasi strategi ini dengan cara melakukan analisis matriks IE pada PT BesQ Sarana Abadi. Tujuan penggunaan matriks IE untuk memperoleh gambaran grand strategy, sehingga perusahaan dapat menentukan harus dikembangkan, dipertahankan atau dilepas. Susun matriks IE maka diketahui posisi perusahaan saat ini, sehingga mempermudah dalam menentukan langka strategi yang akan diterapkan. Hasil matriks IE diperoleh dengan menggabungkan total skor IFE dan total skor EFE ke dalam sumbu X dan Y. Dari hasil matriks IE PT BesQ Sarana Abadi menempati sel VI (Gambar 1) dengan skor terbobot dari faktor internal dan eksternal $(1,79 ; 2,64)$, sehingga menempatkan PT BesQ Sarana Abadi pada posisi harvest and divest (panen atau divestasi). 
Alternatif yang dapat digunakan PT BesQ Sarana Abadi pada kuadran VI adalah daerah panen atau divestasi (harvest and divest). Posisi harvest and divest berusaha memperoleh laba dan arus kas jangka pendek atau menghentikan bsinis tersebut. Posisi harvest and divest ini sesuai dengan kondisi di PT BesQ Sarana Abadi yang mengalami permasalahan pada alur kas (castflow). Strategi yang dibutuhkan menurut matriks IE yang harus dilakukan oleh PT BesQ Sarana Abadi adalah memperoleh laba jangka pendek dan alur kas yang baik. Pilihan untuk menutup usaha tidak dipilih, karena masih ada peluang untuk menjalankan bisnisnya. Matriks IE ini hanya memberikan gambaran secara umum tanpa mempertimbangkan faktor kekuatan dan kelemahan yang ada.

Setelah didapatkan grand strategy dengan matriks IE, selanjutnya membuat matriks SWOT. Matriks SWOT merupakan alat analisis yang menggambarkan alternatif strategi yang dikembangkan oleh perusahaan mempertimbangkan kekuatan dan kelemahan internal, serta peluang dan ancaman eksternal. Hasil analisis SWOT PT BesQ Sarana Abadi dapat dilihat pada Gambar 2.

\begin{tabular}{|c|c|c|c|c|c|c|}
\hline \multirow{5}{*}{$\begin{array}{l}\text { Total skor } \\
\text { terbobot EFE }\end{array}$} & \multirow{2}{*}{4.0} & \multicolumn{5}{|c|}{ Total skor terbobot IFE } \\
\hline & & 4.0 & 3.0 & $2.0^{\prime}(1$ & & 1.0 \\
\hline & 3.0 & $\mathrm{I}$ & II & & III & \\
\hline & $\begin{array}{r}(2.55) \\
2^{-} \overline{0}^{-}\end{array}$ & $-\mathrm{HV}^{-}-$ & $-V^{-}-$ & $-y$ & VI & \\
\hline & 10 & VII & VIII & & IX & \\
\hline
\end{tabular}

Gambar 1. Matriks IE PT BesQ Sarana Abadi

\begin{tabular}{|c|c|c|}
\hline Faktor-faktor Eksternal (EFE) & $\begin{array}{l}\text { Strengths }(\mathbf{S}) \\
\text { 1. Tersedianya mesin untuk } \\
\text { produksi } \\
\text { 2. Tersedianya teknologi } \\
\text { untuk staf } \\
\text { 3. Tersedianya transportasi } \\
\text { untuk pengiriman } \\
\text { 4. Tersedianya SMM ISO } \\
\text { 9001:2015 } \\
\text { 5. Tersedianya teknologi } \\
\text { informasi }\end{array}$ & $\begin{array}{l}\text { Weakness }(\mathbf{W}) \\
\text { 1. Kondisi castflow keuangan } \\
\text { bermasalah } \\
\text { 2. Rejection Rate tinggi } \\
\text { 3. Efektivitas operasional mesin } \\
\text { rendah } \\
\text { 4. Pelatihan terhadap operator } \\
\text { kurang } \\
\text { 5. Mesin yang digunakan mesin } \\
\text { produksi lama } \\
\text { 6. Sistem manajemen mutu belum } \\
\text { dijalankan }\end{array}$ \\
\hline $\begin{array}{l}\text { Opportunites }(\mathbf{O}) \\
\text { 1. Tingginya permintaan kendaraan } \\
\text { bermotor } \\
\text { 2. Pemanfaatan tenaga kerja sekitar } \\
\text { 3. Tren permintaan kendaraan bermotor } \\
\text { stabil } \\
\text { 4. Pelanggan merupakan perusahaan } \\
\text { besar } \\
\text { 5. Besarnya pengguna kendaraan } \\
\text { bermotor } \\
\text { 6. Meningkatnya industri manufaktur }\end{array}$ & $\begin{array}{l}\text { SO (Strengths opportunites) } \\
\text { 1. Meningkatkan penjualan } \\
\text { 2. Meningkatkan } \\
\text { keuntungan } \\
\text { 3. Penambahan jumlah } \\
\text { pelanggan } \\
\text { 4. } \begin{array}{l}\text { Meningkatkan kepuasan } \\
\text { pelanggan }\end{array}\end{array}$ & $\begin{array}{l}\text { WO (Weakness-opportunities) } \\
\text { 1. Meningkatkan kompetensi } \\
\text { karyawan } \\
\text { 2. Mengimplementasikan budaya } \\
\text { kerja efektif }\end{array}$ \\
\hline \begin{tabular}{l}
\multicolumn{1}{c}{ Threats $\mathbf{( T )}$} \\
1. Ketergantungan material sama supplier \\
2. Lingkungan sekitar pabrik kurang \\
mendukung \\
3. Harga BBM naik \\
4. Kenaikan UMR \\
5. Kenaikan listrik \\
6. Melemahnya rupiah \\
\end{tabular} & $\begin{array}{l}\text { ST (strengths-threats) } \\
\text { 1. Mengoptimalkan capaian } \\
\text { produktivitas } \\
\text { 2. Pengiriman produk tepat } \\
\text { waktu } \\
\text { 3. Mempercepat proses design } \\
\text { item baru }\end{array}$ & $\begin{array}{l}\text { WT (Weakness-threats) } \\
\text { 1. Menurunkan material lost } \\
\text { 2. Menurunkan rejection rate } \\
\text { produk dalam proses produksi } \\
\text { 3. Menurunkan rejection rate } \\
\text { produk dari supplier } \\
\text { 4. Menurunkan rejection rate } \\
\text { proses di subcont }\end{array}$ \\
\hline
\end{tabular}


Tabel 3. BSC PT BesQ Sarana Abadi

\begin{tabular}{|c|c|c|}
\hline Perspektif & Strategi & Sasaran \\
\hline \multirow[t]{2}{*}{ Finansial } & $\begin{array}{l}\text { Usaha peningkatan jumlah pelanggan } \\
\text { (SO1) }\end{array}$ & Penambahan Jumlah Pelanggan \\
\hline & & Penjualan Rp 900.000.000/bulan \\
\hline \multirow[t]{2}{*}{ Prelanggan } & $\begin{array}{l}\text { Penambahan item baru pada pelanggan } \\
\text { yang sudah ada }(\mathrm{SO} 2)\end{array}$ & $\begin{array}{l}\text { Penambahan item baru } 2 \\
\text { produk/bulan }\end{array}$ \\
\hline & & $\begin{array}{l}\text { Customer complain maks } 1 \text { kasus } / 3 \\
\text { bulan }\end{array}$ \\
\hline \multirow[t]{3}{*}{ Proses Internal } & $\begin{array}{l}\text { Mengoptimalkan capaian produktivitas } \\
\text { (WT4) }\end{array}$ & $\begin{array}{l}\text { Capaian produktivitas proses min } \\
80 \% \text { dari kapasitas }\end{array}$ \\
\hline & & Ketepatan pengiriman $100 \%$ \\
\hline & Pengembangan metode baru (SO3) & $\begin{array}{l}\text { Katepatan waktu penyelesaian } \\
\text { mold baru } 100 \%\end{array}$ \\
\hline $\begin{array}{l}\text { Learning and } \\
\text { growth (partum- } \\
\text { buhan dan }\end{array}$ & $\begin{array}{l}\text { Meningkatkan kompetensi tenaga kerja } \\
\text { (WO2) }\end{array}$ & $\begin{array}{l}\text { Pemenuhan Kompetensi pegawai } \\
100 \%\end{array}$ \\
\hline pembelajaran) & & Pelaksanaan 5R \\
\hline
\end{tabular}

Hasil analisis SWOT dipola dalam bentuk BSC yang bisa dilihat pada Tabel 3. Balanced Scorecard merupakan alat pengukur kinerja eksekutif yang memerlukan ukuran komprehensif dengan empat perspektif, yaitu perspektif keuangan, pelanggan, bisnis internal, serta pertumbuhan dan pembelajaran. Detail strategi BSC yang diterapkan di PT BesQ Sarana Abadi bisa dilihat pada Tabel 3.

\section{Analisis QSPM}

Matriks QSPM merupakan tahap akhir dari analisis formulasi strategi untuk pemilihan alternatif strategi terbaik. Dari matrik QSPM dapat dilihat nilai TAS (Total Attractiveness Score) tertinggi, yang merupakan alternatif strategi paling cocok untuk dilaksanakan oleh PT BesQ Sarana Abadi

Strategi-strategi yang tercipta didasarkan posisi perusahaan pada matriks IE dan dirumuskan secara lebih mendalam pada matriks SWOT yang dievaluasi tingkat ketertarikan menghadapi peluang dan ancaman yang dihadapi perusahaan dengan kekuatan dan kelemahan yang dimiliki perusahaan. Hasil akhir dari analisis QSPM berupa TAS atau total skor daya tarik yang merupakan penjumlahan hasil perkalian rataan AS atau nilai daya tarik suatu strategi terhadap faktor internal atau eksternal tertentu dengan rataan bobot faktor internal dan eksternal yang telah dirumuskan dalam matriks IFE dan EFE. Nilai TAS yang dihasilkan lalu diurutkan berdasarkan besar nilainya. Urutan nilai TAS menggambarkan urutan prioritas strategi untuk dilaksanakan oleh perusahaan. Strategi dengan nilai TAS tertinggi adalah strategi yang paling diprioritaskan oleh perusahaan untuk mengembangkan pemasarannya. Urutan prioritas strategi berdasarkan matriks QSPM PT BesQ Sarana Abadi diperlihatkan dalam Tabel 4.

Tabel 4. QSPM PT BesQ Sarana Abadi

\begin{tabular}{|c|c|c|}
\hline Strategi & TAS & Prioritas \\
\hline $\begin{array}{l}\text { - Penambahan jumlah } \\
\text { pelanggan }(\mathrm{SO})\end{array}$ & 5,40 & 1 \\
\hline $\begin{array}{l}\text { Penambahan item baru pada } \\
\text { penggan yang sudah ada (SO) }\end{array}$ & 5,34 & 2 \\
\hline $\begin{array}{l}\text { - Mengoptimalkan capaian } \\
\text { produktivitas (WT) }\end{array}$ & 4,85 & 3 \\
\hline $\begin{array}{l}\text { - Mempercepat proses design } \\
\text { new item (SO) }\end{array}$ & 7,11 & 4 \\
\hline
\end{tabular}

\section{KESIMPULAN}

Dari hasil penelitian ini didapatkan matriks IE PT BesQ Sarana Abadi pada posisi sel VI, yaitu posisi harvest and divest dengan strategi keuntungan jangka pendek. Strategi yang dirumuskan melalui analisis SWOT adalah Penambahan jumlah pelanggan (SO), Penambahan item baru pada penggan yang sudah ada (WT), Mengoptimalkan capaian produktivitas (SO), Mempercepat proses design new item (SO). 


\section{DAFTAR PUSTAKA}

Angkasa WI, M. Hubeis, N.K. Pandjaitan. 2012. Strategi dan Kelayakan Pengembangan Lembaga Intermediasi untuk Meningkatkan Daya Saing Usaha Kecil dan Menengah di Indonesia. Jurnal Manajemen IKM, 7(2): 95-101.

David, F.R. 2015. Manajemen Strategi (suatu pendekatan keunggulan bersaing). Salemba Empat

Dwiyanti, R., M. Hubeis, dan G. Suprayitno. 2017. Perumusan Strategi Operasi Produksi Kosmetik (studi kasus PT ANI). Jurnal Manajemen IKM, 12(1): 35-47.

Diany, E., Suryahadi, T. Muhandri. 2016. Strategi Pemasaran Semen Beku Sapi Potong di BIB Lembang.

Fadli, R., M. Syamsun, dan W. Trilaksani. 2017. Perencanaan Strategik Sistem Informasi
Pengembangan Usaha UD Vier 57 Sehat

Bergizi. Jurnal Manajemen IKM, 12(1): 75-83.

Indariawati, P., S. Raharja, S.T. Soekarto. 2011.

Kajian Strategi Pengembangan Usaha Industri Kripik Singkong PT Inti Sari Rasa di Bekasi. Jurnal Manajemen IKM, 6(2): 99-104. Katuruni, I.R., A. Daryanto, dan A. Maulana. 2015. Renstra Bisnis Suku cadangs otomotif Berbahan karet di CV Regina Eka Pratiwi. Jurnal Manajemen IKM, 10(2): 131-142.

Kinner, T.L., Taylor, 1991. Marketing Research an Applied Approch. Frouth Edition. McGraw Hill. New York (US).

Mulyadi. 2007, Sistem Terpadu Pengelolaan Kinerja Personil Berbasis Balance Scorcard, UPP STIM YKPN.

Rangkuti, F. 2017. SWOT Balanced Scorecard Teknik Menyusun Strategi Korporat yang Efektif Plus Cara Mengelola Kinerja dan Risiko. PT Gramedia Pustaka Utama. Jakarta. 